\author{
Jacek Z. Kubiak ${ }^{1,2}$, Agnieszka Kwiatek ${ }^{3}$, Barbara PŁytycz ${ }^{4}$ \\ ${ }^{1}$ Department of Experimental Embryology \\ Institute of Genetics and Animal Biotechnology PAS \\ 36A Posteppu Str., Jastrzębiec, 05-552 Magdalenka \\ ${ }^{2}$ UnivRennes, UMR 6290, CNRS \\ Institute of Genetics and Development of Rennes \\ Faculty of Medicine \\ Rennes, France \\ ${ }^{3}$ Department of Molecular Virology \\ Institute of Microbiology \\ Faculty of Biology \\ University of Warsaw \\ Miecznikowa 1, 02-096 Warsaw, Poland \\ ${ }^{4}$ Department of Evolutionary Immunology \\ Institute of Zoology and Biomedical Research \\ Jagiellonian University \\ 9 Gronostajowa Str., 30-387 Krakow \\ E-mail: j.kubiak@igbzpan.pl \\ jacek.kubiak@univ-rennes1.fr \\ akwiat@biol.uw.edu.pl \\ barbara.plytycz@uj.edu.pl
}

\title{
PANDEMICS. INTRODUCTION
}

Here we present to the Readers of the quarterly KOSMOS a special issue prepared during the COVID-19 pandemic caused by the SARS-CoV-2 coronavirus, which two years ago infected a man and has already killed almost 5 million people from different continents. Epidemics of infectious diseases haunting mankind are so dramatic events in human history that they attract the attention of not only medics and scientists, but also writers and artists. We try to reflect in this issue of KOSMOS.

For the beginning we chose a biography of a Polish traveler-journalist Lucjan Wolanowski (1920-2006) who, secured with appropriate vaccines, documented the situation he found during the outbreaks of plague or cholera (ROTT).

The series of articles (DUDEK and KWIATEK, SANAK, DADOK and SOWA, WITKOWSKI and BRYL, STARZYK et al., KUBIAK) that follows present the current state of knowledge on the genetics, variability and activity of the SARS-CoV-2 virus in the human body and the COVID-19 disease it causes. As probably everyone knows, it can be ei- ther asymptomatic or more or less devastating to the patient's organism, up to a lethal outcome. In this series of articles, our illustrious Authors describe and discuss the reasons for these different outcomes. And it depends, inter alia, on genetic predispositions, age and coexistence of accompanying diseases. The severity of the disease also depends on the individual activity of the human immune system, which - over-stimulated - destroys the body.

Next, we will find article on the prevention of COVID-19 as a droplet-transmitted disease, consisting of covering the mouth and nose with masks, maintaining social distance and observing hand hygiene (KONDRZYCKA-DĄDA et al.). For a year now, we have had vaccines against COVID-19, which prepare the immune system to fight the virus efficiently, thanks to which the vaccinated, but infected patients usually get only slightly sick, avoiding hospitalization and death, which mainly affects unvaccinated people who come into contact with SARS-CoV-2 for the first time (JANKOWI$\mathrm{AK}$ and TRZONKOWSKI). In addition to tradi- 
tional vaccines with inactivated viruses or their genetic material embedded in the genome of harmless adenoviruses for the first time very effective vaccines containing viral mRNA fragments encoding the Spike protein (S) responsible for both recognition of receptors on host cells and penetration into them (JANKOWIAK and TRZONKOWSKI). There are still no effective drugs against COVID-19 (ADAMCZYK-POPŁAWSKA et al.), so prevention is even more important, which, unfortunately, is hampered by the resistance of people who deny the existence of this dangerous virus, as well as anti-vaccination movements that undermine efforts undertaken to mitigate the effects of the pandemic. Social responses to the state of the pandemic are illustrated on the example of France (KUBIAK).

Nowadays, we know that the different variants of the SARS-CoV-2 coronavirus will remain with us forever and we will have to learn to coexist with them. Mathematics provides predictions on the development of a pandemic (FORYŚ et al.), and biologists create in silico, in vitro and in vivo new models to study this, and future pandemics (NowAK et al.). We have no doubts that pathogens are constantly moving between different species inhabiting our globe (GRABOWSKA and ADAMCZYK-POPŁAWSKA). Epidemics and pandemics affect not only the fate of humanity, but also all living creatures, which was illustrated by the example of amphibians (JAKÓBIK and PABIJAN). Modern palaeogenetic research reveals traces of past pandemics in our extinct ancestors and relatives, the Neardentals and Denisovans (MARSZAEEK et al.).

This special issue closes a view of an art historian on the works of artists from different eras related to past pandemics (KRASNY), and one of them illustrates the cover.

We would like to thank the Authors and Reviewers for the effort put into creating this issue.
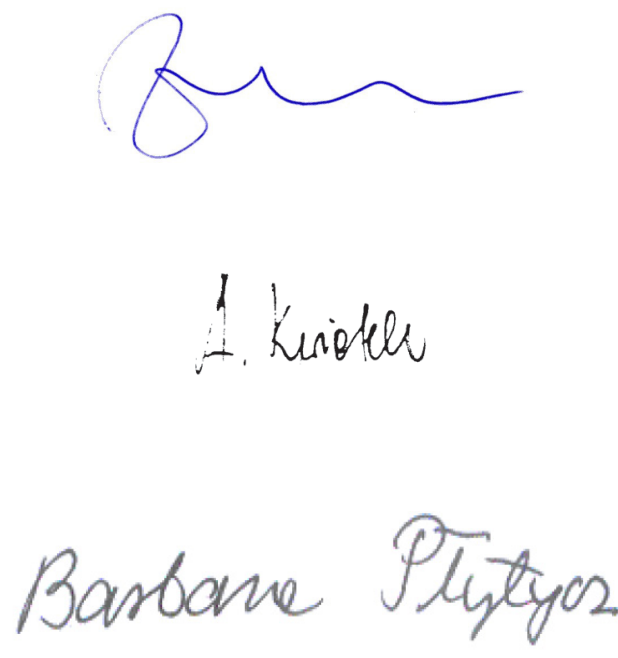